\title{
REORIENTASI KAJIAN USHULUDDIN DALAM MERESPONS TANTANGAN ZAMAN
}

\author{
Muhyar Fanani \\ Dosen Fakultas Ushuluddin IAIN Walisongo Semarang; \\ Kepala Pusat Pengembangan Bahasa IAIN Walisongo Semarang
}

\begin{abstract}
This paper attempts to discuss the various issues on the Islamic theology sciences. As implied in its name, ushuluddin sciences should be the core and kernel of Islamic sciences. In fact, the muslim community were far a way from the ushuluddin sciences. It is caused that the theories in ushuluddin sciences are always referring to a past era and was rarely associated with contemporary social problems. The efforts to develop the Islamic sciences are supposed to leave in advance of the ushuluddin sciences. This paper intends to study the direction of the study sciences ushuluddin in response to the challenges of the times. If the ushuluddin sciences want to continue to exist, then the first thing that must tobe done is to change the scientific paradigm shift from which only oriented itself into a community-oriented.
\end{abstract}

Kata kunci: ushuluddin, tantangan zaman, reorientasi kajian

\section{Pendahuluan}

Dalam era kemajuan sains dan teknologi, ilmu agama terutama ilmu ushuluddin, menghadapi tantangan yang pelik. Masyarakat bertanya bagaimanakah kehidupan sekarang yang pola dan tata nilainya telah berubah bisa dijelaskan secara memuaskan oleh konsep-konsep dasar Islam. Kegagalan para pemerhati ilmu ini menjelaskannya, telah berdampak negatif baik bagi perkembangan ilmu ushuluddin maupun bagi masyarakat muslim. Bagi sebagian kalangan, ilmu ushuluddin itu seakanakan wujuduhu ka 'adamihi. Kondisi ini bukanlah keadaan yang tanpa sebab. Sebab yang paling mudah dilihat adalah karena masyarakat telah tidak merasa mendapatkan kontribusi dari ilmu ushuluddin. Apabila ilmu ushuluddin ingin tetap eksis, maka hal pertama yang mendesak untuk dilakukan adalah merubah paradigma keilmuannya dari yang hanya berorientasi kepada dirinya sendiri menjadi berorientasi kemasyarakatan.

Sudah sekian lama, paradigma ilmu ushuluddin menjauhi praksis masyarakat. Teori-teorinya pun selalu merujuk pada era masa lalu yang jarang dikaitkan dengan problematika sosial kekinian dan kedisinian. Akibatnya mudah ditebak setiap kali ilmu ushuluddin dibicarakan, maka saat itu pula problem irrelevansi muncul. Sebagai contoh adalah teori-teori yang ada dalam ilmu kalam. Dalam ilmu kalam dijumpai teori kekuasaan dan kehendak mutlak Tuhan. Persoalan utama yang menjadi perdebatan para teolog dalam wilayah ini adalah seberapa besarkah pengaruh kekuasaan dan kehendak Tuhan terhadap perbuatan dan kehendak manusia. Teori ini sangat populer di kalangan fakultas ushuludin, namun jarang yang mengembangkannya untuk menjelaskan problematika kontemporer masyarakat. Hasan Hanafi menginginkan adanya paradigma baru kalam yang jelas-jelas lebih memihak pada nasib manusia bukan nasib Tuhan. ${ }^{1}$ Dengan kata lain teori-teori ilmu kalam perlu direorientasikan ulang, bukan semata-mata untuk Allah tapi untuk pencerahan manusia. Bagaimanakah mereorientasikan ilmu kalam? Bagaimanakah mereorientasikan ilmu ushuluddin?

\footnotetext{
${ }^{1}$ Lihat: Hassan Hanafi, Minal 'Aqîdah Ilâ ats-Tsawrah (Kairo: Maktabah Matbuli, 1991).
} 
Sebagaimana tersirat dalam namanya, ilmu-ilmu ushuluddin seharusnya menjadi the core and kernel of Islamic sciences. Upaya pengembangan ilmu-ilmu keislaman sudah semestinya berangkat terlebih dahulu dari ilmu-ilmu ushuluddin. Tulisan ini bermaksud mengkaji arah kajian ilmu-ilmu ushuluddin dalam merespons tantangan zaman. Untuk itu, cakupan ushuluddin harus diklarifikasi terlebih dahulu.

\section{Apa itu Ilmu Ushuluddin?}

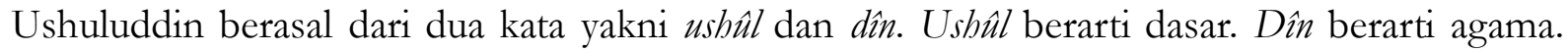
Secara harfiah, ushuluddin berarti dasar-dasar agama. Belum ada data yang pasti kapan istilah ini muncul pertama kali sebagai sebuah istilah yang khusus. Namun istilah ini telah dipergunakan para ahli untuk memberi judul karya mereka. Terdapat paling tidak 6 buku karya para ulama abad XI-XII M, yakni:

1. Ushûluddîn karya Abû Manshûr al-Baghdadî.

2. Asy-Syâmil fî Ushûliddîn karya al-Juwaini.

3. Ushûluddîn karya Abû al-Yusr al-Bazdawî.

4. Tabsyîrât al-Adilla fi Ushûliddîn karya Abû al-Mun'im an-Nasafî (w. 1114).

5. Al-Mu'tamad fi Ushâliddîn karya Qadhi Abu Ya'lâ.

6. Al-Mu'tamad fi Ushûliddîn karya al-Malâhimi al-Mu'tazili (w. 1141).

Apa maksud ushuluddin dalam buku-buku di atas? Ternyata maksudnya tiada lain adalah ilmu kalam. Bahkan ushuluddin itu hanyalah nama lain dari ilmu kalam. ${ }^{2}$ Dengan demikian wajar jika terdapat seorang penulis memberikan judul bukunya dengan Fi Ilm al-Kalam: Dirasah Falsafiyyah li Ara' al-Farq al-Islamiyyah fi Ushul ad-Din. ${ }^{3}$ Beberapa penulis menyetujui pandangan ini. ${ }^{4}$

Bila dalam tradisi keilmuan Islam, ushuluddin berarti ilmu kalam, apakah fakultas ushuluddin itu berarti fakultas ilmu kalam? Ternyata tidak. Fakultas ushuluddin lebih mengacu pada pembidangan ilmu agama Islam yang pernah dikeluarkan oleh LIPI. Menurut LIPI, ilmu agama Islam dapat dibidangkan menjadi 8 bidang. Pembidangan LIPI ini hingga kini masih menjadi landasan formal studi Islam di IAIN dan Perguruan Tinggi Agama lainnya:

1. Sumber ajaran Islam
a. Ilmu-ilmu al-Quran
b. Ilmu tafsir
c. Ilmu hadits

2. Pemikiran dasar Islam
a. Ilmu tauhid/kalam
b. Filsafat Islam/tasawuf
c. Perbandingan agama

3. Hukum Islam dan pranata sosial
a. Usul fikih
b. Fikih Islam

${ }^{2}$ First Encyclopaedia of Islam 1913-1936 (Leiden: E.J. Brill, 1987) VII: 1054; The Encyclopaedia of Islam, ed. P.J. Bearman et.al. (Leiden: E.J. Brill, 2000) X: 930; The Encyclopaedia of Islam (Leiden: E.J. Brill, 1971) III: 1141-1150.

${ }^{3}$ Ahmad Mahmud Shubhi, Fi Ilm al-Kalâm: Dirâsah Falsafiyyah li Ara' al-Farq al-Islâmiyyah fi Ushûl ad-Dîn (Beirut: Dar anNahdhah al-Arabiyyah, 1985).

${ }^{4}$ Mahmud Syaltut, al-Islâm Aqîdah wa Syarîah (Ttp:Dar al-Qalam, 1966), 55; Ali Sami an-Nasysyar, Manâhij al-Babltsi Inda Mufakekir al-Islâmî Wa Naqd al-Muslimin li al-Mantiq al-Aristotolisi (Ttp: Dar al-Fikr Al-Arabi, 1947), 67-74. 
c. Pranata sosial

d. Ilmu falak dan hisab

4. Sejarah dan peradaban Islam
a. Sejarah Islam
b. Peradaban Islam

5. Bahasa dan sastra Islam

a. Bahasa Arab

b. Sastra Arab

6. Pendidikan Islam

a. Pendidikan dan pengajaran Islam

b. Ilmu jiwa Islam

7. Dakwah Islam

a. Dakwah Islam

8. Perkembangan Modern/Pembaharuan dalam Islam

a. Perkembangan Modern/Pembaharuan dalam bidang sumber ajaran

b. Perkembangan Modern/Pembaharuan dalam bidang pemikiran dasar Islam

c. Perkembangan Modern/Pembaharuan dalam bidang fikih dan pranata sosial

d. Perkembangan Modern/Pembaharuan dalam bidang sejarah dan peradaban Islam

e. Perkembangan Modern/Pembaharuan dalam bidang bahasa dan sastra Islam

f. Perkembangan Modern/Pembaharuan dalam bidang pendidikan Islam

g. Perkembangan Modern/Pembaharuan dalam bidang Dakwah Islam

Berdasarkan pembidangan LIPI itu, ushuluddin atau dasar-dasar agama mencakup 3 bidang ilmu yakni ilmu tauhid/kalam, filsafat Islam/tasawuf, dan perbandingan agama. Tiga bidang ilmu itu digolongkan dalam rumpun pemikiran dasar Islam. Dengan demikian, fakultas ushuluddin terlihat lebih mengacu pada pandangan LIPI daripada pandangan ulama abad XI-XII M. Pandangan LIPI itu saat ini sedang menghadapi tantangan.

Dengan semakin rendahnya minat masyarakat untuk masuk ke Fakultas Ushuluddin, para pengelola fakultas ini mulai membuka area studi baru. Fakultas Ushuluddin IAIN Walisongo, misalnya, telah membuka Jurusan Tasawuf dan Psikoterapi serta Jurusan Perbandingan Agama dan Resolusi Konflik. Namun pertanyaannya, sesungguhnya apa objek material dan objek formal ilmu ini? Pertanyaan ini penting dijawab untuk mengetahui batas-batas ilmu ushuluddin. Pengembangan ilmu ini sudah semestinya menaati batas-batas tersebut.

Setiap ilmu memiliki objek material dan objek formalnya sendiri. Dua objek ilmu inilah yang membedakan antara ilmu satu dengan ilmu yang lain. Ilmu kedokteran, misalnya, objek materialnya adalah tubuh manusia. Sementara objek formalnya pengenalan penyakit dan penanggulangannya. Kedokteran berbeda dengan antropologi ragawi. Padahal objek materialnya sama yakni tubuh manusia. Namun objek formalnya berbeda. Antropologi ragawi lebih mengkaji peninggalan-peninggalan raga manusia untuk diketahui karakter fisik dan cara hidup mereka dalam sejarah umat manusia. Apa objek material dan objek formal ilmu ushuluddin?

Objek material ilmu ini sesungguhnya tidak hanya ilmu kalam namun mencakup tiga pilar yang menjadi dasar tegaknya Islam sebagai sebuah agama. Tiga dasar itu adalah Iman, Islam, Ihsan. Ilmu yang terkait dengan Iman dinamakan aqidah. Ilmu yang terkait dengan pilar kedua disebut syari'ah. Semetara ilmu yang berhubungan dengan pilar ketiga disebut akhlaq. Tiga pilar ini mengacu pada hadis Nabi Muhammad berikut: 


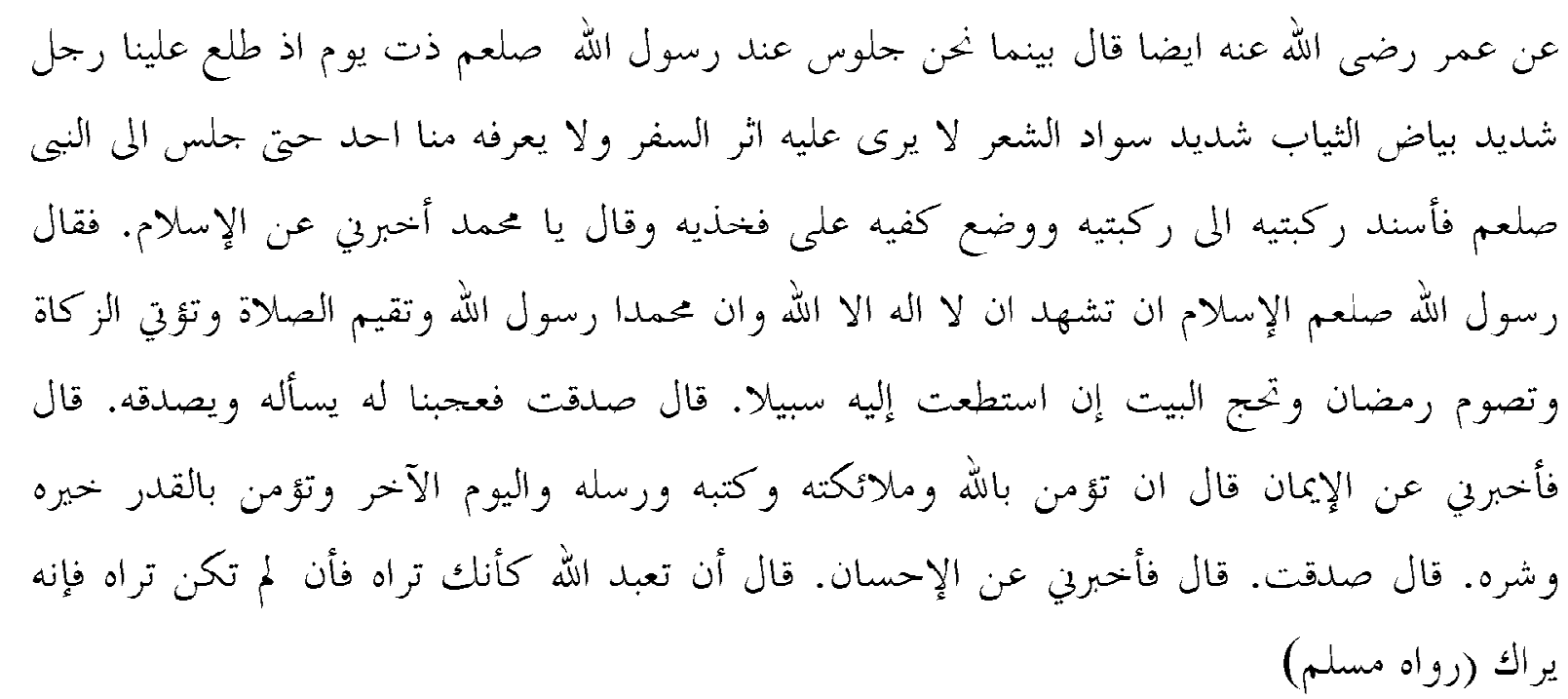

Bila objek materialnya adalah Iman, Islam, Ihsan, lantas apa objek formal ilmu ushuluddin? Mengacu pada karya-karya ulama abad X-XII di atas, maka objek formalnya adalah pemikiran yang mendasar, radikal, tuntas, baik dengan cara dialektis (debat, jadal), maupun demonstratif (pembuktian) terhadap tiga pilar di atas atau yang terkait dengan ketiganya. Pemikiran mendasar tentang Iman telah dirintis oleh ulama penggagas ilmu aqa'id yang disebut juga dengan ilmu kalam itu. Menurut para sejarahwan, pendiri ilmu ini adalah ulama mu'tazilah yang dikenal sangat rasional, tuntas, radikal dalam membuktikan adanya Tuhan dan sifat-sifat suci-Nya. Dalam perkembangannya, rintisan ulama Mu'tazilah itu terus dikembangkan walaupun ulama Mu'tazilah ditekan bahkan dihabisi karena banyak penguasa yang merasa tidak nyaman dengan pemikiran mereka. ${ }^{5}$

Pemikiran mendasar tentang syariah dinamakan ilmu ushul fiqh. Ilmu ini sangat rasional, tuntas, dan radikal dalam menggali syariah agar bisa dipertanggungjawabkan secara rasional dan demontratif (valid). Ilmu ini walaupun dianggap sebagai milik fakultas syari'ah namun sesungguhnya akar dari ilmu ini adalah ushuluddin. Salah satu kitab babon ilmu ini yang berjudul al-Amd ditulis oleh Qâdhî Abdul Jabbâr yang tiada lain adalah ulama Mu’tazilah yang ahli dalam ilmu kalam. Begitu juga syarah kitab tersebut yang berjudul al-Mu'tamad. Kitab ini ditulis oleh murid Qadhi Abdul Jabbar yang bernama Abul Husain al-Bashrî yang juga beraliran Mu’tazilah. Itulah makanya debat-debat dalam ilmu ushul figh selalu melibatkan para ulama kalam terutama saat membahas darimanakah sesungguhnya manusia mengenal baik dan buruk; dari akal atau wahyu. ${ }^{6}$

Pemikiran mendasar tentang akhlak dilakukan oleh ulama-ulama akhlak dan tasawuf. Ilmu falsafah akhlak dan tasawuf sesungguhnya ilmu inti dari ushuluddin. Pertanyaan seputar mengapa manusia harus berbuat baik? Pertanyaan ini telah banyak didiskusikan oleh para ulama akhlak. Begitu pula pertanyaan mengapa manusia harus dekat dengan Tuhan? Bagaimanakah caranya? Ulama tasawuf memiliki diskusi yang mendalam tentang hal ini.

Bila kajian yang mendasar, radikal, tuntas, dialektis, demontratif tentang tiga pilar itu baru dinamakan kajian ushuluddin, maka kajian tentang tiga pilar itu yang tidak dilakukan secara mendasar, radikal, tuntas, dialektis, demontratif bukanlah kajian ushuluddin. Namun, kajian yang mendasar terhadap selain tiga pilar itu masih bisa dinamakan ushuluddin asal dilakukan dengan menggunakan objek formal ushuluddin. Inilah yang dilakukan oleh al-Ghazali dalam Kitab al-Arba'in fi Ushuliddin.

\footnotetext{
${ }^{5}$ Muhyar Fanani, Pudarnya Pesona Ilmu Agama (Yogyakarta: Pustaka Pelajar, 2007), 39-86.

${ }^{6}$ Abdul Wahhab Khallaf, Ilmu Ushul Fiqh (Ttp: Darul Qalam, 1978), 96-99.
} 
Walaupun judulnya ushuluddin, al-Ghazali sesungguhnya bicara tema yang lebih luas baik yang mencakup topik inti ushuluddin maupun yang bersifat non inti seperti amaliyah ibadah keseharian. ${ }^{7}$ Begitu pulalah yang terjadi dalam ilmu kedokteran. Walaupun yang dipelajari bukan tubuh manusia namun menggunakan perspektif kedokteran masih bisa disebut kajian kedokteran. Kedokteran hewan adalah contohnya. Ia mempelajari hewan namun menggunakan objek formal ilmu kedokteran.

\section{Tantangan Zaman}

Objek material ilmu ushuluddin dapat disederhanakan menjadi tiga pertanyaan, yakni:

1. Bagaimana agar manusia percaya pada Allah? Pertanyaan ini merupakan pertanyaan dasar ilmu akidah. Pertanyaan ini bisa dikembangkan dalam $5 \mathrm{~W}+1 \mathrm{H}$ (what, who, why, which, when, dan how). Apa/siapa itu Allah, mengapa harus percaya pada Allah, Allah yang mana yang harus dipercayai, kapan harus mempercayainya merupakan pertanyaan penting seputar iman yang harus dijawab oleh ilmu kalam.

2. Bagaimana agar manusia taat pada perintah-Nya? Pertanyaan ini adalah pertanyaan dasar ilmu syari'ah. Apa itu taat, mengapa harus taat pada Allah, taat yang bagaimana yang harus dilakukan, kapan harus taat merupakan pertanyaan penting seputar syariah yang harus dijawab oleh ilmu ushul fiqh.

3. Bagaimana agar manusia mau berbuat baik? Pertanyaan ini merupakan pertanyaan dasar ilmu akhlak. Apa itu baik/buruk, mengapa harus ada baik/buruk, perbuatan baik yang bagaimanna yang harus dilakukan, kapan harus berbuat baik merupakan pertanyaan penting seputar akhlak yang harus dijawab oleh ilmu akhlak/tasawuf.

Seiring dengan perkembangan zaman, terutama perkembangan IPTEK yang dengan cepat merubah pola hidup dan tata nilai masyarakat, persoalan ketiga objek material di atas semakin mendesak untuk dicarikan jawabannya secara mendasar pula. Pertanyaan seputar peran Allah dan peran manusia dalam sebuah peristiwa menjadi pertanyaan yang membutuhkan jawaban baru pasca revolusi teknologi. Pertanyaan tentang ini, memaksa sarjana ushuluddin untuk membuka kembali diskusi tentang takdir. Konsep takdir pasca revolusi sains dan teknologi harus mendudukkan lima hal yakni Allah, manusia, hukum sebab-akibat (causality), mu'jizat, dan doa. 


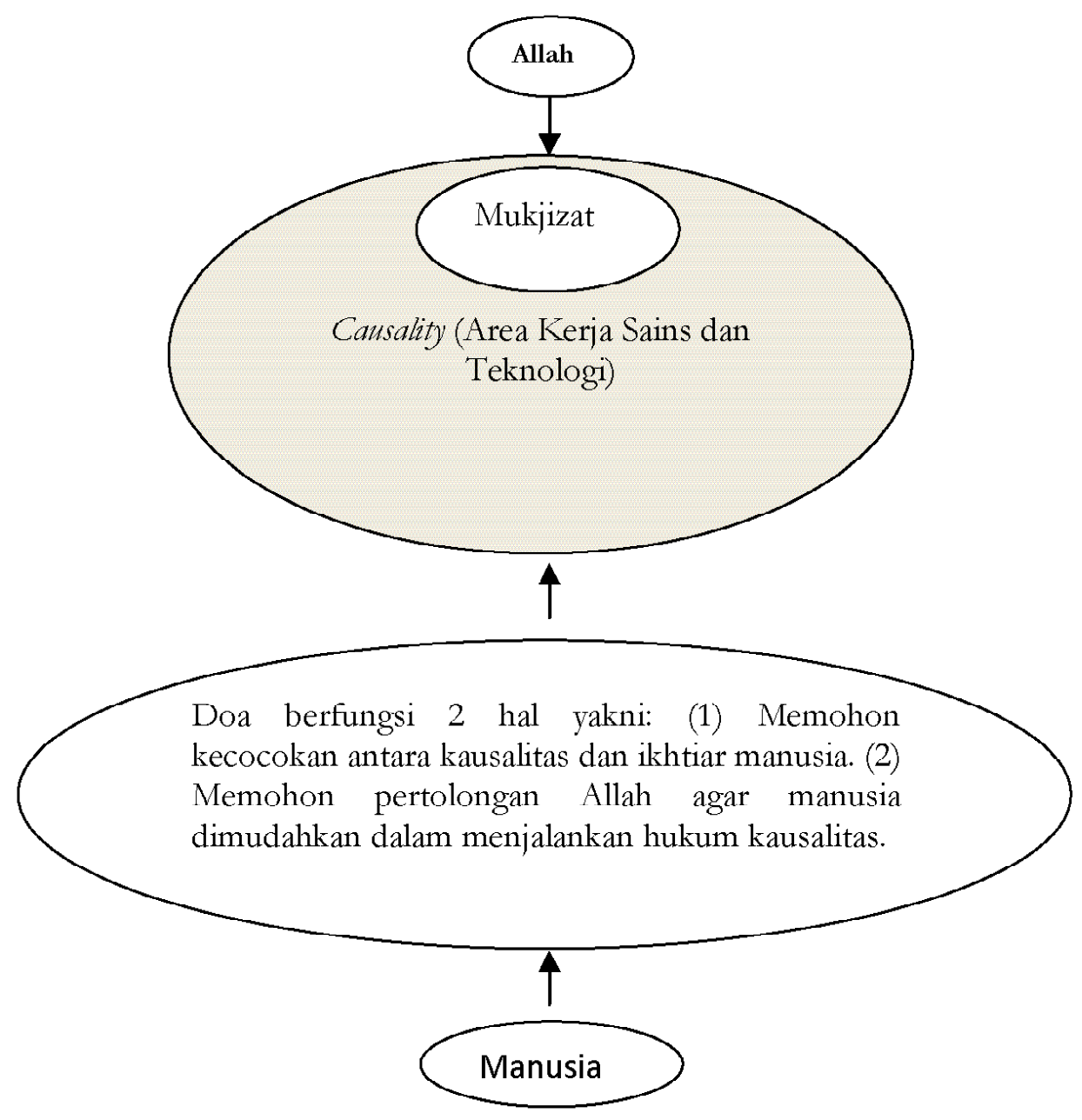

Pertanyaan tentang suatu peristiwa apakah lebih merupakan peristiwa sebab akibat atau mukjizat pada era kemajuan sains dan teknologi menjadi pertanyaan yang rumit. Si anak yang bernama Agus Istiqlal lahir melalui operasi cesar tanggal 17 Agustus 2013 bisa menjadi bahan diskusi menarik. Pemilihan tanggal lahir itu lebih merupakan fenomena kausalitas atau mukjizat atau doa atau kehendak Allah atau kehendak manusia? Bila kita merujuk argumentasi Al-Ghazali tentu jawabannya adalah iradah Alllah. Namun bila kita setuju dengan pandangan Ibnu Rusyd tentu jawaban atas pertanyaan di atas adalah kausalitas.

Al-Ghazali memerankan manusia sebagai wayang. Ibn Rusyd memerankan manusia sebagai makhluk bebas yang bisa bertindak apa saja. Ilmu kalam modern harus bisa menjelaskan konsep takdir pasca revolusi sains dengan sejelas-jelasnya. Penjelasan itu harus lebih jelas pada era sekarang daripada era al-Ghazali dan Ibn Rusyd mengingat era dua pakar itu (abad ke-11 hingga ke-14 M) belum ada kemajuan sains dan teknologi seperti sekarang ini. Gambar di atas menunjukkan bahwa baik kausalitas maupun mukjizat itu bersumber dari Allah. Maka menjalankan kausalitas berarti juga menjalankan ketentuan Allah. Orang Barat tidak memiliki konsep ini sehingga bagi mereka kausalitas dinamakan hukum alam. Menaati kausalitas dianggap menaklukkan alam. Mereka tidak mengenal konsep menaati Tuhan sang pencipta Alam.

Orang beriman memiliki konsep yang berbeda dengan Barat dalam memahami suatu kejadian. Allah menurunkan dua macam sistem tentang suatu peristiwa, yakni hukum kausalitas (sunnatullah) dan mukjizat. Sunnatullah diberi porsi yang jauh lebih besar dari pada mukjizat. Katakanlah 90\% melawan 10\%. Allah hanya akan menurunkan mukjizat-Nya sesekali saja. Mayoritas kejadian 
menggunakan hukum kausalitas. Mengapa Allah menurunkan mukjizat? Karena Allah menginginkan manusia tidak menuhankan hukum kausalitas. Itulah makanya sesekali Allah menunjukkan mukjizatNya. Mukjizat berarti peristiwa yang menyalahi hukum kausalitas. Bila seseorang ingin mendapatkan suatu kesuksesan dengan probabilitas yang tinggi maka jalan yang benar bukanlah merayu Allah untuk menurunkan mukjizat-Nya, melainkan menjalankan hukum kausalitas Allah. Mengapa? Karena hukum kausalitas jauh lebih sering terjadi atas izin Allah daripada mukjizat-Nya. Lantas dimanakah fungsi doa?Doa berfungsi 2 hal yakni: (1) Memohon kecocokan antara kausalitas dan ikhtiar manusia. (2) Memohon pertolongan Allah agar manusia dimudahkan dalam menjalankan hukum kausalitas.

Untuk berlatih memahami konsep takdir ini, saya memiliki pertanyaan. Dalam sangkar di bawah ini terdapat dua burung yang besar temboloknya berbeda. Burung dengan tembolok besar memakan makanan yang lebih banyak. Pemilik burung, secara rutin memberi jatah makanan dan minuman. Pertanyaannya, perbedaan besarnya tembolok kedua burung itu ditentukan oleh burung itu sendiri atau oleh pemilik?

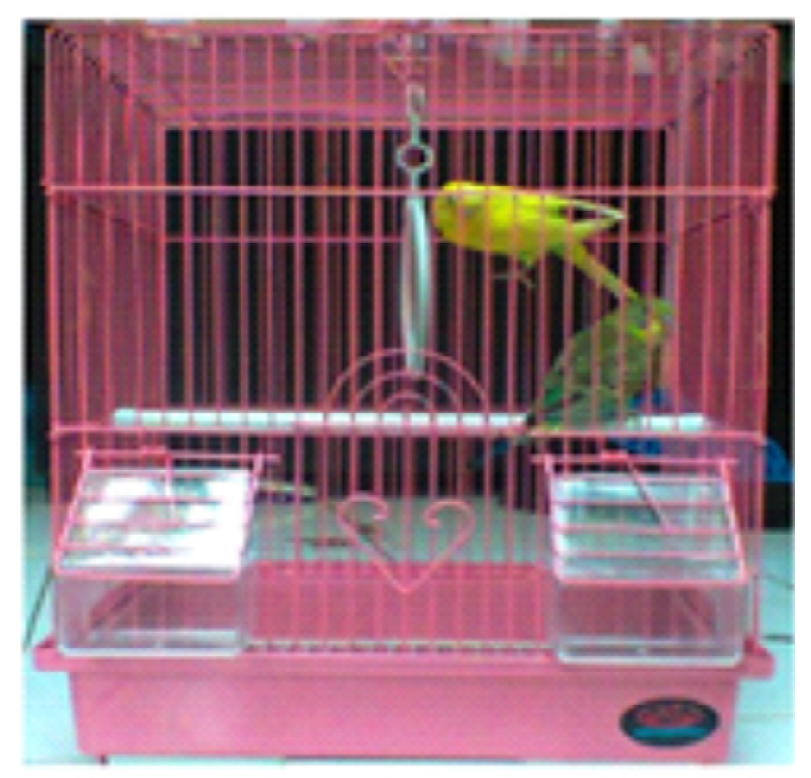

Kajian mendalam tentang pertanyaan-pertanyaan baru pasca revolusi sains dan teknologi dalam area akidah, syariah dan akhlak amat sangat diperlukan dewasa ini. Itulah area kerja sarjana ushuluddin. Saat ini penjelasan seputar gejala baru dalam area ini masih belum tersentuh secara baik. Sebut saja sebagai contoh, mengapa orang Indonesia yang mayoritas asy'ariyah (bukan qadariyah/mu'tazilah) yang tentu secara doktriner lebih banyak pasrah tapi kenyataannya dalam urusan keuangan ternyata korup. Padahal korupsi adalah wujud dari ketidakpasrahan seseorang atas pembagian rizqi dari Allah. Bagaimana menjelaskannya?

Pertanyaan lain seputar karakter manusia Indonesia yang beragama namun aneh juga menarik. Mochtar Lubis pernah menyatakan enam ciri manusia Indonesia. Salah satunya adalah enggan bertanggung jawab. ${ }^{8}$ Ini hingga kini masih terlihat di Indonesia. Pejabat yang jelas salah kalau tidak dipaksa tidak akan mau mundur. Bahkan dia akan mencari kambing hitam. Bila orang beriman, pasti dia meyakini bahwa siapa berbuat pasti bertanggung jawab. Itu adalah hukum dasar asas kebebasan bertindak sebagaimana didiskusikan para ulama kalam. Tapi mengapa orang Indonesia yang berketuhanan Yang Maha Esa justru menyalahi hukum Tuhan?

\footnotetext{
${ }^{8}$ Mochtar Lubis, Manusia Indonesia: Sebuah Pertanggungjawaban (Jakarta: Yayasan Idayu, 1980).
} 


\section{Reorientasi Kajian}

Pertanyaan-pertanyaan mutakhir tentang kehidupan masyarakat menuntut pengkaji ushuluddin untuk terus berpikir. Pertanyaan-pertanyaan itulah sesungguhnya arah orientasi kajian ushuluddin yang tepat agar ilmu ushuludin tidak mengalami irelevansi dari masyarakat. Untuk mempermudah penjelasan, saya akan menggunakan pola yang lazim dalam perumusan rencana kajian ilmiah yang meliputi perumusan masalah, kajian riset terdahulu, kerangka teori, dan metode.

\section{Perumusan Masalah}

Sudah disinggung pada bagian di atas bahwa area kajian ushuluddin mencakup iman, Islam (syariah), dan ihsan (akhlak) dan yang lainnya asalkan punya kaitan dengan tiga pilar itu dan dikaji dengan menggunakan pendekatan yang mendasar, radikal, mendalam, dialektis, dan demonstratif. Untuk S1, biasanya pertanyaan diarahkan pada pertanyaan "apa”. Untuk S2 diarahkan pada pertanyaan "bagaimana". Sedang untuk S3 diarahkan pada pertanyaan "mengapa". Masalah keushuluddinan dapat digali dengan sistem bulkonah (bulat, kotak, daan panah). ${ }^{9}$ Ilustrasi sistem ini adalah sbb:

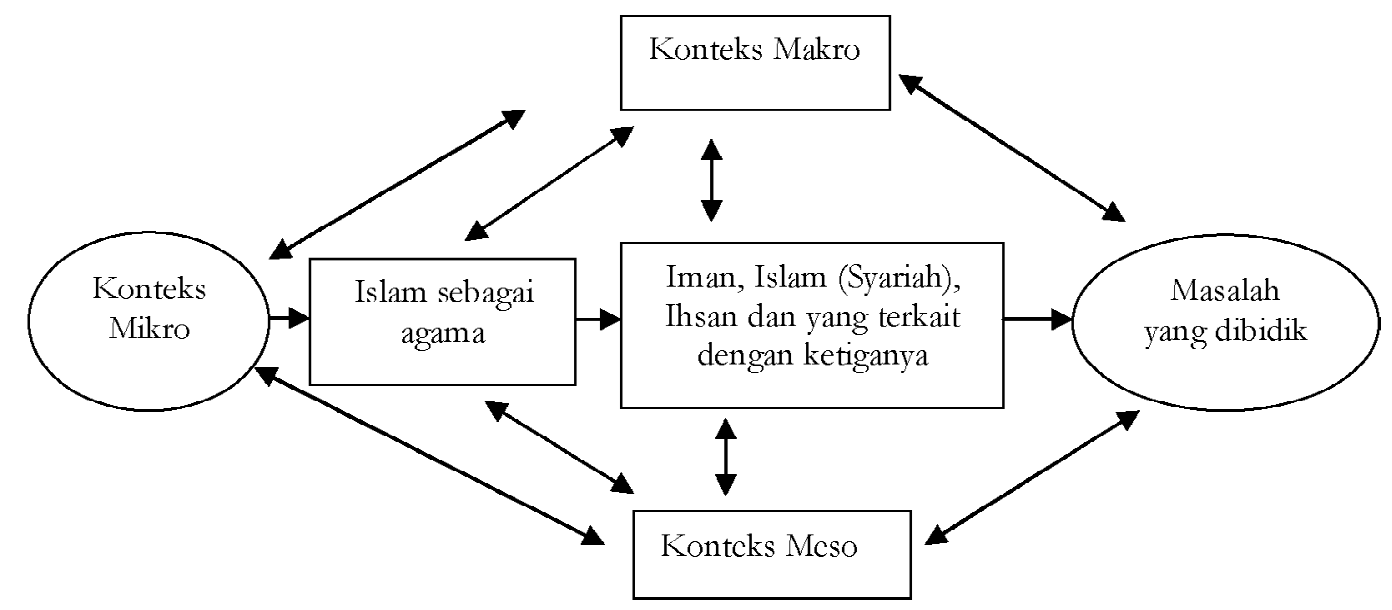

Setiap kajian sebaiknya hanya memfokuskan satu masalah agar bisa tuntas dan mendalam. Satu masalah itu dapat diurai menjadi beberapa anak masalah yang biasanya dirumuskan menjadi pertanyaan-pertanyaan penelitian.

\section{Kajian Riset Terdahulu}

Telaah pustaka amat penting dalam kajian ushuluddin. Mengapa? Telaah pustaka akan memancing ide baru. Ide baru biasanya muncul dari hasil riset terbaru. Masa berlaku buku atau hasil riset biasanya hanya 10 tahun. Untuk itu telaah pada jurnal penelitian sangat penting karena jauh lebih mutakhir bila dibanding dengan buku. Perlu dipahami telaah pustaka berbeda dengan kerangka teori. Telaah pustaka mengkategorikan kepustakaan dan positioning riset yang sedang dikerjakan. Sementara kerangka teori masuk lebih dekat pada isi pustaka. Maka telaah pustaka tidak menyebut isi rinci suatu referensi tapi isi umum suatu referensi. Telaah pustaka yang baik terhadap khazanah mutakhir masalah ushuluddin akan mengantarkan pengkaji menemukan posisinya dalam dunia kajian keushuluddinan.

\section{Kerangka Teori}

Dalam kajian keushuludinan, kerangka teori amatlah penting. Kerangka teori akan membantu pengkaji dalam menjawab masalah penelitian. Kerangka teori berisi kerangka, bukan teori. Kerangka

\footnotetext{
${ }^{9}$ Ceramah Irwan Abdullah, Hotel Kencana Bandungan, 12 Mei 2014.
} 
teori adalah kerangka pikiran pengkaji yang dibangun dari teori-teori terdahulu yang relevan dengan masalah penelitian. Teori adalah penjelasan suatu gejala yang didalamnya menyebutkan adanya relasi (hubungan). Contoh teori yang terkenal adalah $\mathrm{E}=\mathrm{MC}^{2}$. Teori itu disebut teori relativitas. Teori bukanlah definisi. Definisi tak pernah mencantumkan relasi sementara teori harus mencantumkannya. Untuk riset normatif seperti ilmu ushuluddin, penggunaan kerangka teori yang dibangun dari teoriteori mutakhir akan menjadikan riset normatif terasa lebih hidup, menggigit, dinamis dan kritis. Teori itu akan menjadi objek formal atau persektif sementara objek materialnya adalah riset keushuludinan tersebut yang rata-rata bersifat normatif. Perlu dicatat bahwa kerangka teori merupakan manifestasi dari sebuah pendekatan/paham/paradigma yang dipergunakan oleh seorang pengkaji.

4. Metode

Dalam rancangan suatu kajian, metode mencakup penjelasan seputar 5 hal yakni: lokasi, jenis penelitian dan data, sumber data, teknik pengumpulan data, teknik analisis data. Lokasi kajian keushuluddinan mencakup tempat, institusi, upacara, peristiwa, teks, tokoh, atau konsep keushuluddinan. Jenis penelitian dapat bersifat ekploratif, kualitatif, dan eksplanatif. Sementara datanya bisa primer dan sekunder. Sumber data dapat diambil pada lokasi kajian seperti di atas. Teknik pengumpulan data kajian ushuluddin bisa survey, observasi, interview, analisis isi, atau dokumentasi. Adapun teknik analisis datanya selalu menggunakan teknik analisis yang relevan namun harus bersifat mendalam, tuntas, dan radikal. Analisis filosofis sangat cocok untuk riset-riset ushuluddin.

\section{Penutup}

Demikianlah sekelumit pandangan tentang reorientasi kajian ushuluddin dalam merespons tantangan zaman. Secara singkat dapat dinyatakan bahwa pertanyaan-pertanyaan mutakhir tentang kehidupan masyarakat merupakan arah orientasi kajian ushuluddin yang tepat agar ilmu ushuludin tidak mengalami irelevansi dari masyarakat. Dalam teori seleksi alam dinyatakan bahwa makhluk hidup yang bisa beradaptasi dengan perkembangan baru, dialah yang bisa bertahan hidup. ${ }^{10}$ Ilmu Ushuluddin juga demikian. Bila ilmu ini bisa menjawab tantangan zaman, maka ilmu ini akan eksis. Namun bila tidak, ilmu ini akan mati. Tugas kita bersama, para pemerhati ilmu ushuluddin, untuk menjadikan ilmu ushuluddin tetap jaya. Jalannya tiada lain adalah jawablah pertanyaan-pertanyaan mutakhir tentang fenomena hidup masyarakat, kaitkan fenomena itu dengan tiga pilar Islam di atas.

\section{Daftar Pustaka}

Hanafi, Hassan, (1991). Minal 'Aqîdah Ilâ ats-Tsawrah, Kairo: Maktabah Matbuli.

Bearman, P.J. et.al. (ed), (1987). First Encyclopaedia of Islam 1913-1936 Leiden: E.J. Brill.

Shubhi, Ahmad Mahmud, (1985). Fi Ilm al-Kalâm: Dirâsah Falsafiyyah li Ara' al-Farq al-Islâmiyyah fi Ushûl ad-Dîn, Beirut: Dar an-Nahdhah al-Arabiyyah.

Syaltut, Mahmud, (1966). al-Islâm Aqî̉ah wa Syarîah, Ttp: Dar al-Qalam.

Nasysyar, Ali Sami an-, (1947). Manâhij al-Baḅtsi Inda Mufakekir al-Islâmî Wa Naqd al-Muslimin li alMantiq al-Aristotolisi, Ttp: Dar al-Fikr Al-Arabi.

${ }^{10}$ Charles Taylor, The Concise Science Encyclopedia (New York: Kingfisher, 2001), 39. 
Muhyar Fanani, (2007). Pudarnya Pesona Ilmu Agama, Yogyakarta: Pustaka Pelajar.

Khallaf, Abdul Wahhab, (1978). Imu Ushul Fiqh, Ttp: Darul Qalam.

Al-Ghazali, (1988). Kitab al-Arba'in fi Ushuliddin, Beirut: Darul Jail.

Lubis, Mochtar, (1980). Manusia Indonesia: Sebuah Pertanggungjawaban Jakarta: Yayasan Idayu.

Taylor, Charles, (2001). The Concise Science Encyclopedia, New York: Kingfisher. 